\title{
Letter from Australia
}

\section{Coming of age}

\section{Anthony R Moore Department of Surgery, University of Melbourne, Royal Melbourne Hospital, Victoria, Australia}

In Australia, as in many Western countries, the population is ageing. In coming decades we can anticipate that the medical care of the elderly will claim an increasing proportion of medical and economic resources. It will also confront us with an expanding challenge in the ethical issues affecting the aged.

One can easily define the ingredients in the Antipodean problem but the solutions are not so obvious. The population of Australia is ageing: in 19014 per cent of the population was over 65 years and in 1976 the figure was 8.7 per cent; in 1901 8.3 per cent of the population had celebrated their 5oth birthday while in 197622 per cent reached their half century. Further, for the elderly of today, survival following illness is more common. Previously an acute illness in an old person often led to death. Now sickness frequently results in a residual disability for which care must be offered. In earlier days there were the 'quick and the dead', but today there are the "quick and the elderly who are not quite so quick'. Another factor that will increase the number of people pushed towards the geriatric group is the early retirement schemes being adopted to help offset unemployment in the young.

The first problem is clear: an increase in the number who will require geriatric services. The second problem - which serves to frustrate and subvert attempts to effect this care - is the containment and reduction of medical resources and spending, and the increasing cost of medical care.

There are many other unfortunate seams in the geology of geriatric care. One is the inevitability of ageing and its associated medical problems. Apart from the correction of sociogenic factors and attitudes towards the elderly - which are difficult to reverse quickly little can be done to prevent the effects of ageing. Another is the breakdown of the family unit and the decreasing responsibility of offspring for the care of parents, together with a style of life leading to greater individual mobility and geographic separation, both of which undermine essential community supports for the elderly.

If one adds to these some unfeeling policy decisions being made by health insurance companies and governments in relation to the infirm and chronically ill, we are left with a sense of discomfort about the probegbility of adequate future care for the elderly.

What are the ethical issues which will arise as a resutt of a progressive increase in the age of the population believe these issues will involve government, societ the family, the profession and individual practitionems - and for convenience they can be considered unde्cि these headings.

\section{Government}

Governments will need to decide the order of medicad spending and the place which geriatric care will have that hierarchy. Of course, in part, this will depend $\vec{O}$ political philosophy but it will also involve ethical de sions on the priorities of spending on research, hospital services or community services. More specificall $\overrightarrow{b 6}$, Governments will be involved in decisions relatigg provision of housing for the elderly. They will needdo have guidelines on the accommodation needs of the aged and may need to consider mortgage adjust memt and borrowing schemes designed to bring about effetive housing. Decisions can be anticipated on appropriateness of supplementary schemes for both housing and sickness benefits. Special concessiog could be offered to families prepared to accept thie responsibility for the care of their elderly relative Recently in Australia there has been grave concern expressed about the standard of care in privat, profit-making, special accommodation for the elder $\vec{P}$. State Government officials have promised an investiga tion and a review of the legislation in this area.

Predictions have been made that in the future eldegy patients will need to be an effective organised political lobby.

\section{The community}

It is not a cynical observation that society is onby interested in 'successful' agers who do not stress be community or make demands on its resources. Frigl old age is regarded as failed old age - a state of dependency. An important ethical area involves the attituate of a society to its elderly. A society usually has unspoken philosophy in relation to the usefulness of its dependants, and also in its sociogenic attitudes towards age. Society does impose a role on people as they readh a certain chronological age. Insofar as this is unjustifif we have sociogenic forces which undermine the elderly. Frequently, a transition to senior years or in 
retirement exposes an individual to social attitudes which make a capable person feel unintelligent, unemployable, asexual and socially inadequate. Modern research indicates that many of the mental and human changes seen in senior people are not biological effects of ageing but are due to their fateful acceptance of a part imposed on them by an unfeeling society. It has been said that society's prejudices against the elderly indoctrinate us while we are young but affect us when we are old. The trouble with the part the community assigns to the elderly is that it is a destructive part which reduces self-esteem and self-sufficiency. In turn, this leads to dependency and to a further strain on community resources. In youth we sharpen knives which cut our own wrinkled throats in years to come. By ignoring the needs of a vulnerable minority which we are inevitably going to join, we are burying ourselves.

Social attitudes towards the elderly are destructive and one possible prophylaxis against them is a modification of our view of our life purpose. At the moment our education is vocation and work orientated. It is certainly not life orientated. As Alex Comfort has said 'we are educated to act as a one way projectile which at the end of our trajectory is designed to explode'. By educating for general abilities and interests related to the non-vocational aspects of our lives, we can avoid a sense of demeaning idleness and uselessness as each of us moves to a situation where we do not work but still have time to be creative individuals.

More specifically, each member of society is involved with decisions concerning self and selflessness. Most geriatric patients can benefit from volunteer groups, particularly those assisting stimulation programmes. Music, group singing, craftwork and even simple company all can have beneficial effects.

Certain groups within society which accommodate only members of their own group in non-profit hostel accommodation may need to give a justification for that policy when the needs of non-members are greater than some of their 'own kind'. Community services offered for preventive geriatric care can assist with information about resources, and pre-treatment counselling can be of benefit to counteract destructive socio-genic pressures. Such services will be determined by the availability of community funds and resources.

The community as a whole will need to define its attitude towards health insurance companies, particularly those loading premiums for the chronically ill. A related but independent issue is the responsibility of all members of society to make provision for the management of their assets in preparation for old age. The offer of superannuation and retirement schemes, and of the availability of schemes which stimulate young members of society to allocate their resources to provide for their aged years, are basic to this issue. This could involve employing organisations and employees in ethical decisions about the desirability of compulsory participation in such schemes. It would also involve governments in policies which recommend compulsory superannuation.

\section{The family}

All families which have elderly dependants are involved in decisions on the degree of their commitment to the care of their relatives. Together with the doctor, the family may be involved in ethical decisions in relation to offers of home support, decisions on whether to treat the patient, and for taking the responsibility for decisions for a patient who mav be incapacitated.

\section{The profession}

Among the ethical issues which concern the profession are, first, our basic attitude towards care of the elderly. In the past, when care has been indicated on medical or social grounds, the patient has been admitted to the hospital. In recent times, it has been recognised that social frailty without associated specific medical problems is best cared for in the home. Even when specific medical problems are present, their correction can be followed by a rapid return to the community and its supporting resources. This is the desired objective of enlightened geriatric care.

The majority of patients who come to geriatric hospitals arrive from the community. Modern geriatric thought is directed towards increasing the number who are able to return to their home or community rather than to special accommodation, long term care homes or geriatric public hospital beds. A proportion o geriatric patients die during the course of their admise sion. For those who improve it has been shown that an? active policy in relation to home discharge can reduce very considerably the number of patients who continue to use valuable geriatric hospital resources. At Mount Royal Hospital for the aged in Melbourne, the active pursuit of this policy has resulted in only 22 per cent of patients admitted being accommodated in long-term hospital care. This is a considerable reduction from the number in past years, but it is dependent on the effi ciency of social workers, the sense of responsibility in the family, and the availability of community resources. Another approach being practised is tc review all patients who have been long-term patients and to see if some can be discharged. At Mount Royal Hospital, over one quarter of such patients were happily housed away from the major hospitals.

Aside from questions of philosophy, the medical profession, the universities and the research grant organisations will have to decide on their priorities for research spending and the allocation for hospital resources. And it takes no imagination to realise that the euthanasia debate may become very active.

\section{Doctors and associated professionals}

Among the many ethical issues which will concern individual members of the medical professions will be: the decision to treat elderly incurable patients; the decision to operate on elderly patients; the dilemma of soliciting the views of a confused or eccentric or 
demented patient; the handling of a patient who refuses treatment against medical advice; the conflicts which could arise with selfish or over involved relatives; the unfortunate necessity of occasionally splitting dependent elderly couples - and many others.

Doctors will have additional responsibilities for the accurate documentation of the incidence of diseases in the elderly. It is virtually impossible to predict or estimate morbidity in the elderly. Over the age of 75 , it is thought that nearly 65 per cent of patients have some disability; however, there is a hidden incidence of morbidity. Unreported illnesses such as defects in vision, senility, musculoskeletal deficiency, feet prob- lems and urinary problems are very common but often unrecorded. In part this is an effect of the attitude of patients who regard such symptoms as normal for theif age rather than evidence of an active disease process. The professionals and the doctors will have the respoffsibility adequate documentation and reporting $\overrightarrow{f f}$ statistics on disease incidence in the elderly.

Someone has said that one can judge the morality society by the way it treats its young, its infirm and elderly. Adequate planning and forethought - wi humanity as a large factor in the decision making - of the care of the elderly could lead to a situation where our societies can feel a sense of self respect.

\section{Medical groups}

\section{Further information on Medical Groups}

For fuller details, complete lecture lists are available from the secretaries of the medical groups listed below. Please enclose a stamped addressed A4 envelope.

ABERDEEN MEDICAL GROUP

Dr James Hendry and Dr David Hood, Medical buildings, Foresterhill, Aberdeen AB9 22D

BIRMINGHAM MEDICAL GROUP Dr Anthony Parsons, Department of Obstetrics, Birmingham Maternity Hospital, Edgbaston. Birmingham Brs

BRISTOL MEDICAL GROUP

Dr Martin London, 1 I Somerset Street, Kingsdown, Bristol BS2 8NB

CAMBRIDGE MEDICAL GROUP Mr Patrick Doyle, Department of Urology, Addenbrooke's Hospital, Hill's Road, Cambridge
CARDIFF MEDICAL GROUP

Dr Jonathan Richards, Flat 2,

I Howard Gardens, Routh, Cardiff

DUNDEE MEDICAL GROUP Dr Douglas Shaw, Department of Pharmacology and Therapeutics, University of Dundee, Nine Wells Hospital, Dundee

EDINBURGH MEDICAL GROUP Dr Brian Potter, EMG Project Office, 24 Buccleuch Place, Edinburgh EH 8 9LN

GLASGOW MEDICAL GROUP Dr Valerie Kyle, 8 Crown Road North, Glasgow GI2 9DH

LIVERPOOL MEDICAL GROUP Dr Colin Powell, Dept of Medicine, Royal Liverpool Hospital, Liverpool L7 8XP
LONDON MEDICAL GROUP

Director of Studies, 68 Tavistock

House North, Tavistock Square

London WCIH 9LG

MANCHESTER MEDICAL GROUP Dr Mary Lobjoit, Teaching Unit 4 O University Hospital of South Manchester, Nell Lane, West Didsbury, Manchester M20 8LR

NEWCASTLE MEDICAL GROUP Dr Christopher Drinkwater, 14 Beliè Grove Terrace, Newcastle-upon-Ty NE $24 \mathrm{LL}$

OXFORD MEDICAL FORUM Dr James Falconer Smith, 20 Park Close, Bladon, Oxon OX 7 IRN

SHEFFIELD MEDICAL GROUP Dr Martin Hayes-Allen, 183 Whitha周 Road, Broomhill, Sheffield Sio 2SBN

SOUTHAMPTON MEDICAL GROUP Dr T R M Billington, 56 Glen Eyreo Road, Southampton $\mathrm{SO}_{2} 3 \mathrm{NJ}$ 